\title{
Announcement
}

\section{First International \& Eighth European Conference on Clinical Hemorheology}

Lecture Halls of the Medical Faculty, University of Vienna, Austria

July 5-8, 1993

Chairman: E. Ernst, Vienna

The bi-annual European Conferences have been traditionally the main platform for researchers not only from Europe but from all over the world. The organizers therefore feel the time is right for instituting an International as well as a European meeting. The meeting attempts to emphasize the clinical aspects of hemorheology and to account for the diversity of specialties directly involved into this type of research.

The scientific program includes plenary lectures, symposia, workshops, poster presentations, round table discussions and other events. The links with other medical, particularly clinical specialties will be stressed. Main topics will be, among others:

O Biophysics

O Cardiovascular, cerebrovascular, and peripheral vascular risk factors and diseases

O Epidemiology

O Experimental models

O Hematology

O Hemorheological drug mechanisms

O Hemostaseology

O Inflammation and acute phase response

O Non-pharmacological modification of blood rheology

O Methodology and standardization

O Microcirculation

O Plasma expanders and blood substitutes

O Prostanoids

O Red cells, White cells, Platelets

O Rheologically active drugs: treatment, mode of action

O Vessel wall interaction

Deadline for submission of abstracts: February 15, 1993.

Early registration at a substantially reduced fee will be possible until March 31, 1993.

For further information, please contact the Local Organizing Committee

\author{
$\mathrm{ICCH} / \mathrm{ECCH}$ Congress Secretariat \\ Prof. E. Ernst, Dept. Phys. Med. Rehab. \\ University of Vienna (AKH) \\ Währinger Gürtel 18-20 \\ A-1097 Vienna, Austria
}

Tel: $+43 / 1 / 40400-4330$ - Fax: $+43 / 1 / 40400-5281$ 